\title{
A Review of Factors Considered by the Athletes on Accepting their Sport Coaches
}

\author{
Dias Ren Trevor ${ }^{1}$, \& Vidya N. ${ }^{2}$ \\ ${ }^{1}$ Research Scholar, College of Social Sciences \& Humanities. Srinivas University, \\ Mangalore, Karnataka, INDIA. \\ Orchid ID: 0000-0003-0796-8244, Email: rentrevor@gmail.com \\ ${ }^{2}$ Assistant Professor, College of Social Sciences \& Humanities, Srinivas University, \\ Mangalore, Karnataka, INDIA. \\ Orchid ID: 0000-0002-3390-3390-567X, Email: vidyakrithi.n@ gmail.com
}

Area/Section: Business Management.

Type of the Paper: Review Paper.

Type of Review: Peer Reviewed as per $|\mathrm{C}| \mathrm{O}|\mathrm{P}| \mathrm{E} \mid$ guidance.

Indexed in: OpenAIRE.

DOI: https://doi.org/10.5281/zenodo.5105186

Google Scholar Citation: IJMTS

\section{How to Cite this Paper:}

Trevor, Dias Ren, \& N., Vidya, (2021). A Review of Factors Considered by the Athletes on Accepting their Sport Coaches. International Journal of Management, Technology, and Social Sciences (IJMTS), 6(1), 321-329. DOI: https://doi.org/10.5281/zenodo.5105186

International Journal of Management, Technology, and Social Sciences (IJMTS) A Refereed International Journal of Srinivas University, India.

CrossRef DOI: https://doi.org/10.47992/IJMTS.2581.6012.0148

(C) With Author.

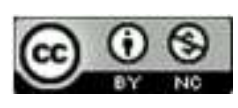

This work is licensed under a Creative Commons Attribution-Non-Commercial 4.0 International License subject to proper citation to the publication source of the work.

Disclaimer: The scholarly papers as reviewed and published by the Srinivas Publications (S.P.), India are the views and opinions of their respective authors and are not the views or opinions of the SP. The SP disclaims of any harm or loss caused due to the published content to any party. 


\title{
A Review of Factors Considered by the Athletes on Accepting their Sport Coaches
}

\author{
Dias Ren Trevor ${ }^{1}$, \& Vidya N. ${ }^{2}$ \\ ${ }^{1}$ Research Scholar, College of Social Sciences \& Humanities. Srinivas University, \\ Mangalore, Karnataka, INDIA. \\ Orchid ID: 0000-0003-0796-8244, Email: rentrevor@ gmail.com \\ ${ }^{2}$ Assistant Professor, College of Social Sciences \& Humanities, Srinivas University, \\ Mangalore, Karnataka, INDIA. \\ Orchid ID: 0000-0002-3390-3390-567X, Email: vidyakrithi.n@ gmail.com
}

\begin{abstract}
Purpose: In India, out of 62 percent of youth population only 1 percent of youths are only taking sports have a profession. In today's context sports have been grown to an industry and a large number of career opportunities are available. Sports coaching is one as such. The sports coaches are the major stake holders in promoting their trainees to the higher level in the game. Coaches are considered a role model by young trainees. Since then, there will be many expectations and beliefs on the coaches'. Players benchmark the targets set by their coaches' to attain their goals. Coaches give intrinsic \& extrinsic motivation for trainees by engaging and involving them in the sport. This is paper has taken a systematic review to understand the players' perception and expectations on their coaches. Basis of secondary data that the challenges occurring in front of coaches for their sustainability in the field of coaching Design/Methodology/Approach: The thematic analysis is done by extracting the codes from the literature. This paper is built on the basis of secondary data that the challenges occurring in front of coaches for their sustainability in the field of coaching. The online platform is used to make desktop research. Around 50 research articles have been closely and systematically reviewed to find the research gap.
\end{abstract}

Findings/Result: The parameters such as support in career goal accomplishment, knowledge on technical component, relational skills, talent search capability and coaching style leads to coaches' capability and competency level. The different theories are reviewed to understand the efficiency and effectiveness in coaching pedagogy. In this study, the deductive codes have been extracted by the literature and analysed to build the concepts. It also rivals the significance of educating and updating the coaches' on regular basis.

Paper Type: Thematic analysis

Keywords: Career goal accomplishment, knowledge on technical components, coaching style, talent search capability, capability and competency level.

\section{INTRODUCTION :}

According to the census today India is the second richest country in terms of human resource [1]. India lacks the sporting culture and environment. Tracing the history of India's performance at the Olympic Games, the nation did not produce even a single individual medalist from 1936 to 1992. By putting to best use, sports provide a host of benefits such as physical and mental health, encourages individuals to take responsibility and promotes teamwork. In India, sports as a career have been gaining importance among young enthusiasts in recent times. A survey conducted by Edu sports in 2017, revealed that India will have a large chunk (estimated 726 million) of its population below 30 years of age by 2030, and it will be important for the future generation to involve in sports to maintain a healthy lifestyle [2]. Career opportunities in sports are on the rise and more sports career related pathways are available for coaches, fitness trainers, managers, sports scientists, dieticians and sports physios, especially after the introduction of professional sports leagues, owned and sponsored by various corporate houses in India. Coaching is an interpersonal ability that makes others proficient in a specific skill. Sports coaching have conveyed a rebellion in enhancing the players' performance output. Nowadays, corporate 
organizational structured flavor had been added to the sports sector. In sports coaching, participants are made to demonstrate and orient themselves into performing specific physical actions. The harmonious passion for coaching by the coaches' will lead to positive behavioral relationships with athletes who drive toward the goal attainment [3]. They deeply investigate the technical, Physical \& Mental aspects of the players for suggesting the required remedies for the errors [4]. The progression in technology has enriched the standard in delivering knowledge to the players' by the coaches. Coaches' need to possess abilities such as a good guide, philosopher, trainer, mentor, educator, thinker, good communicator, good listener and good motivator. The customized pattern and trend changing in the coaching have shown the significance in coaches' up gradation. Athletes evaluate the coaches' competency level in different dimensions, such as motivation, game-strategy, technique, skills detecting abilities and character building. This will lead to coaching competency in positive consequences from the trust among players and coaches. Competency relationship is robust in the team level than the individual level [5]. The revenue of sports coaching industry in US has increased up to $\$ 8.9$ billion from to 2015 to 2020 [6]. Coaches play a significant role in shaping players professionally. Athletes consider coaches as role models and benchmark on the target set by them to attain their career in sports. The players' acceptance of their coaches is from different prospective such as innovativeness in engaging and involving trainees in the game. This study aims at the various aspects considered by the players' on their coaches. The succeeding sections provide a brief review and narration on the literature, which examines the players' acceptance on their sports coaches based on their capabilities and competency level. The different types of theories are also reviewed and discussed underpinning coaching approaches by the coaches'.

\section{RELATED WORK PLAYERS ACCEPTANCE ON THEIR SPORT CACHES :}

\subsection{Coach's Role in Adolescent's Sports Career Choice:}

The long-term performance excellence accuracy and career attainment pathway are established by the coaches through understanding the maturity level of soccer player. Accurate prediction was among the late maturing athletes, while the prediction was poor among early maturing athletes [7]. Coaches' quality to be harmoniously passionate with athletes positively predicted autonomy-supportive behavior but negatively predicted controlling behaviors [8]. Conflicting views in expectations between coaches and athletes were found coaches mentioned only performance objectives, whereas, athletes were also interested in developmental objectives to yield positive development outcomes [9].

\subsection{Coaches' Knowledge \& Technical Components:}

Coaches' lack with injury profiling mechanism, physical \& mental recovery knowledge. The major reason for injuries are over use of body by continues playing. In secondary school sport around 50 percentage of the players is pressurized to play with injury for the reason of desire to win and not letting team down [10]. Coaches intercept the freedom of choice leading to the feeling of lack of self-belief in their own ability, disengagement from practice, a feeling of not being a part of the team (intrinsic motivation). This situation makes a sports person feel that their cognitive needs are not fulfilled anymore and they are not improving their performance. Loss of enjoyment and lack of pleasure associated with a particular sport in the reason for the drop from sport. Negative effects of family environment does not act as a booster to dropping out from sports. Devoting too much time toward sports and the consequences it has toward the daily life routine are extrinsic motivations leading to drop out. Positive contributions of sports toward life are the adaptation to sport culture, self-development and health. Negative contributions are the privation of other experiences for the sake of sports [11]. The athletes progress their life skills, and learn to respect elders by understanding the guidelines of the sport. Field hockey is a sport where the athletes develop family relationships with the entire team unity, friendship, togetherness, and feeling part of a group. Coaches take effort to create a positive environment in the field where the athletes can have fun has well as learn. Coaches try to be friendly with the athlete; the implicit approach is taken into consideration for athletes. Coaches' education instead of more focusing on the technical skills of a coach should be focused more on psychological aspects of coaching [12]. In India, 50 percent of sports coaches lack with the knowledge of technical component [13]. 


\subsection{Talent Search Capabilities:}

Coaches as social agents to the athlete's influence autonomy, whereas, peers who work and play with their equals, influence competence and relatedness [14]. Coaches take up several qualities such as mentors, educator and motivator to stimulate good metal health for the athletes. Due to the lack of metal health education the coaches were unable to assess and address about the athletes mental stability issues. Coaches perceive that the robust relationship with parents will help understand the players' upbringing [15]. Parents opined that the male adolescents' athletes are poor in seeking help on mental health. Coaches acting have a gatekeeper would be a positive and encouraging role for promoting the players mental health. The effective communication, supportive climate, and strong relationship among players and coaches are the motivation for a positive outcome [16].

\subsection{Emotional \& Relational Skills:}

The continuous encouragement by the coaches will change the achievement directions and incentivize the athletes. Coaches' can foster positive \& pleasant experiences for the athletes. And provides expressive tutoring on skill mastery opportunities, and intrinsically motivating sport experiences from one season to the next [17].

\subsection{Coaching Styles:}

The different innovative style of coaching and coaches' behavioral characteristics associated with longterm commitment, continuous motivation and intension perceive sport among athletes [18]. Coaches recognize prosocial and antisocial behavior among early adolescent athletes. Players with prosocial behavior will have good sportsmanship were as players with antisocial behavior will lack with the sportsmanship and relatedness with the teammates and coaches [19]. The Transitional leadership, Transformational leadership, Neutral leadership, Lassies fair leadership and Toxic leadership are the different leadership behaviors of the coaches' influences in the potential areas to improve the skills and motivate the players in Canadian soccer club [20]. The motivational climate in the team and its relationship with players' commitment is analysed by the team coaches' designate an association between perceived motivational climate and pledge [21]. Positive development helps in achieving multiple benefits in sports. Such as physical, emotional and relational level. The intervention programs toward positive development should have key components such as competence, confidence, caring, connections and character. Positive development has five main themes coaching philosophy, coaching outcomes, coach education, leadership and coaches' intervention. The education that the coaches perceive it should have the values based learning that can promote positive development [22]. High demanding coaching role has got the negative character in their work-life balance. Coaches opined that they lack with the opportunity in spending time to interact with the players. Since they are not encouraged with institutional support and were asked to work for long hours for low income lead to the problem of financial security to run their families. It is found that in Australian soccer league's coaches are aware of their role but they are limited by the external forces [23]. Coaches believed that life skill development is a byproduct in sports. Investing time on training would be a challenge for coaches to teach life skills. Even though life skill training should not feel like the old traditional learning, it should be in an interesting and modern self-learning where the players should inculcate in their daily routine [24].

\subsection{Players' Acceptance on Coaches' Capabilities \& Competencies:}

The coaches' competency and coaching behavior is closely related to players' outcome. The coaches' efficacy predicted by the players in the team atmosphere in soccer game. Players rated the coaches' by the team performance in league stages by considering the game strategy efficacy and leadership style in leading to the higher performance of the team [25]. The value of social learning approaches designs the deliverance in the coaching. Coaches should update and refresh their knowledge frequently. Coaches' educator should be placed in the system that influences the potentiality of the coaches' in considering the reflective and critical incidents in open-mind [26].

Table 1: Thematic analysis: Deductive codes from players' expectations on their sport coaches from Literature.

\begin{tabular}{|l|l|}
\hline Codes & Concepts \\
\hline The Career attainment pathway is established by the sport coaches. [18] & \\
\hline
\end{tabular}




\begin{tabular}{|c|c|}
\hline Caches prediction on players' career is likely to be more accurate. [18] & \multirow{2}{*}{$\begin{array}{l}\text { Coach's Role in Adolescent's } \\
\text { Sports Career Choice }\end{array}$} \\
\hline $\begin{array}{l}\text { The good relationship between athletes' and coaches will yield positive } \\
\text { development outcome. [20] }\end{array}$ & \\
\hline Coaches lack with injury profiling mechanism. [21] & \multirow{5}{*}{$\begin{array}{l}\text { Coaches' Knowledge \& Technical } \\
\text { Components }\end{array}$} \\
\hline $\begin{array}{l}\text { The negative influence of the coaches will lead to the players' } \\
\text { disengagement from practice. [22] }\end{array}$ & \\
\hline Coaches take efforts to create a positive environment in the field. [23] & \\
\hline Coach should be focused more on psychological aspects of coaching. [23] & \\
\hline Sports coaches' lack with the knowledge of technical component [24]. & \\
\hline Coaches understand players' competence and relatedness. [25] & \multirow{3}{*}{ Talent Search Capabilities } \\
\hline $\begin{array}{l}\text { Lack of metal health education the coaches were unable to assess and } \\
\text { address about the athletes mental stability issues. [26] }\end{array}$ & \\
\hline $\begin{array}{l}\text { The effective communication, supportive climate, and strong relationship } \\
\text { among the players and the coaches are the motivation for a positive } \\
\text { outcome. [27] }\end{array}$ & \\
\hline $\begin{array}{l}\text { The continuous encouragement by the coaches will change the } \\
\text { achievement directions. [28] }\end{array}$ & Emotional and Relational Skills \\
\hline $\begin{array}{l}\text { The innovative style of coaching will lead to the long-term commitment } \\
\text { between the athletes and the sport coaches. [29] }\end{array}$ & \multirow{6}{*}{ Coaching Styles } \\
\hline $\begin{array}{l}\text { The different ways leadership will make an impact player' response } \\
\text { toward the coaches. [30] }\end{array}$ & \\
\hline $\begin{array}{l}\text { Motivational climate established by the team coaches will influence on the } \\
\text { team performance. [32] }\end{array}$ & \\
\hline $\begin{array}{l}\text { Positive development has five main themes coaching philosophy, } \\
\text { coaching outcomes, coach education, leadership and coaches } \\
\text { intervention. [33] }\end{array}$ & \\
\hline $\begin{array}{l}\text { Coaches are asked to work for long hours for low-income lead to the } \\
\text { problem of financial security to run their families. [34] }\end{array}$ & \\
\hline Life skill development is a by-product in sports. [35] & \\
\hline $\begin{array}{l}\text { The coaches' efficacy predicted by the players in building team } \\
\text { atmosphere. [36] }\end{array}$ & \multirow[t]{2}{*}{$\begin{array}{l}\text { Players' Acceptance on Coaches' } \\
\text { Capabilities \& Competencies }\end{array}$} \\
\hline $\begin{array}{l}\text { Coaches' educator should be placed in the system to refresh the } \\
\text { knowledge of the coaches. [37] }\end{array}$ & \\
\hline
\end{tabular}

\section{OBJECTIVES :}

1. To understand the players' expectation on their coaches.

2. To know the various parameters considered by the players on their coaches acceptance.

3. To notify the significance of getting updated by the coaches to meet the current meet the players' expectation and drive them to their career path way in sports.

4. To suggest strategies in improvising the coaching standards.

\section{METHODOLOGY USED :}

This paper is built on the basis of secondary data that the challenges occurring in front of coaches for their sustainability in the field of coaching. The online platform is used to make desktop research. Around 50 research articles have been closely and systematically reviewed to find the research gap. In addition to analyzing the coaches' behavioral aspects and coaching efficiency the various theories have been reviewed and discussed. The various concepts have been built by extracting the codes from the literature.

\section{RESEARCH GAP :}

This study has referred the national and international research context in terms of players' acceptance mechanism on their coaches.

India is a developing economy which lacks the sporting culture. The efforts of sports coaches are the one, which promotes the players' to the higher level of sport. It was found that the players accept their 
coaches in the various aspects. This study in above successive literature is used to analyze codes on the players' expectation on their coaches' capability and competency level.

\subsection{Research Questions:}

R1. What parameters considered by the athletes in accepting their sport coaches?

$\mathrm{R} 2$. What is the significance of coaches' role in players' career attainment?

R3. How coaches' enhance their coaching ability?

\section{RESULTSAND DISCUSSIONS :}

In every training session or game, it is the role of the coach to help players make sense of the experience and understand the wider context of the game. During the briefing session after a game or practice session, the coach should set up a learning environment for the players where the good bits are appreciated and the areas of improvement are highlighted. The finish should be on a positive note regardless of the result of the performance. Negative remarks, especially during a team meeting will damage the confidence of the player. The act of persuading a player to convince flaws in the game and feedback given in the right circumstances will give a feeling to the player that the coach is committed to improving his/her game. Coach's role as a feedback and solution providers is critical, as players can be very despondent if they are not supported. In the successive analyses the codes have been extracted from the literature and used to build the concept. Coaches give a direction to the players' in reaching their career goals by setting short-term targets. There should be strong bonding between coaches' and the players'. The mental stability of the players needs to be analysed by the coaches. Hence, the positive relationship between both will help coaches' to understand the phase of what trainees are facing in preparing them self to the event. The major challenges are faced by the coaches' are in creating the team environment and building the confidence among the players in driving team for the success. In building the team coaches has make understand to the players' about their responsibility in the team. Coaches has dearth of time to invest with trainees. Coaches are made to work for long hours for less payment, which in stabilise their financial condition. To understand the coaches' in-depth about their coaching pedagogy different theories have been reviewed and related to the study.

Competence is the basic driver to reach a desired level of self-fulfilment. Need for achievement and engagement in activities are predispositions to the need to feel competent [27]. Some classical works like the theory of motivation consider human motivation based on types of needs; basic needs, psychological needs, need for safety; need for self -fulfilment, which includes self-actualization needs [28]. Using social network analysis and game theory, coaches and sports practitioners can simulate practice-learning environment to enhance performance [29]. Self- determination theory examine the intrinsic \& extrinsic inspiration of an athletes that support the individuals' personality. Advancement in the standard of performance \& satisfaction of developing the best practices to progress their behavioral outcome in the self-contribution to the team [30]. Self-confidence is the state of mind of an individual athlete on their perceptions that distinguish the successful and unsuccessful sports career pathway. Individual belief on their own ability, self-concept, self-esteem, and performance anticipations will describe their performance outcome [31]. The theory of achievement highlights the significance for psychological stability and consider the successive addictions in the performance of an individual with previous outcomes and their imitating effect [32]. On sports practice explicates cognitive needs. Social and performance needs that influence an individual's motivation toward sports [33]. Theory Motivation influences the efficiency of sports activities and the level of achievement of athletes depends on the sports skills obtained by the individual. Motivation regard to a specific sport and the stages of sports career will encourage sports career progression [34]. The theory of mindfulness facilitates the fulfillment of basic psychological needs, positive and negative effects, life satisfaction, and subjective strength measurements. The robust ability to train athletes mind and put them in the best situation to compete and to increase the players' performance ability [35]. Planned behavioral theory will establish prediction accuracy in career decision-making, self-efficacy, and career exploration behavior in sports [36]. The applicable grounded theory puts out the theoretical clarifications in what way athletes apply the skills in their everyday lives that they have learned in sport [37].

\section{CONCULUSION :}


Eventually sports as become profession to many. Sports coaches play a significant role in players' development. Today there is a lot of updated system of coaching in existence. Players consider various aspect in terms of finding their coaches. The coaches must represent skilful in front of players' and parents. Coaches' need to possess good communication skills, which help them in building a bondage with the trainees by understanding them in-depth. Updating the knowledge on technical components on the regular basis will improve the efficiency and effectiveness in coaching. The innovative things brought in by the coaches' will lead to the players' engagement and involvement in sport. The study had found that motivation given by the coaches take a major role in adolescents' continuing the sports professionally. The qualities of the coaches such as talent-searching capabilities among the players', emotional relationship skills, coaches' knowledge on technical components and coaching style will lead toward players acceptance on their coaches. India lacks with sports ecosystem. Some projects need to be initiated in the rural part of the country. Imitative also need to be taken in educating the coaches and mapping them to improve the sports in the corners of the country.

\section{REFERENCES :}

[1] https://www.statista.com/search/?q=indian+population\&Search=\&qKat=search

[2] United Nations General Assembly, seventy-third session, (2018). Sports for development and peace, agenda, item12, A/73/L, 36. Retrieved online from, https://stillmed.olympic.org/media/Document\%20Library/OlympicOrg/News/2018/12/Sport-asan-enabler-of-sustainable-development-EN.pdf.

[3] Karoly, P., \& Ruehlman, L. S. (2006). Psychological "resilience" and its correlates in chronic pain: findings from a national community sample. Pain, 123(1-2), 90-97.

[4] Evans, B. (2017). Sports coaching as action-in-context: using ethnomethodological conversation analysis to understand the coaching process. Qualitative Research in Sport, Exercise and Health, 9(1), 111-132.

[5] Kao, S. F., Hsieh, M. H., \& Lee, P. L. (2017). Coaching competency and trust in coach in sport teams. International Journal of Sports Science \& Coaching, 12(3), 319-327.

[6] https://www.ibisworld.com/united-states/market-research-reports/sports-coaching-industry/

[7] Cripps, A. J., Hopper, L. S., \& Joyce, C. (2019). Can coaches predict long-term career attainment outcomes in adolescent athletes?. International Journal of Sports Science \& Coaching, 14(3), 324328.

[8] Kim, I., Lee, K., \& Kang, S. (2019). The relationship between passion for coaching and the coaches' interpersonal behaviors: The mediating role of coaches' perception of the relationship quality with athletes. International Journal of Sports Science \& Coaching, 14(4), 463-470.

[9] Santos, F., Corte-Real, N., Regueiras, L., Dias, C., Martinek, T. J., \& Fonseca, A. (2019). Coaching effectiveness within competitive youth football: youth football coaches' and athletes' perceptions and practices. Sports Coaching Review, 8(2), 172-193.

[10] Whatman, C., Walters, S., \& Schluter, P. (2018). Coach and player attitudes to injury in youth sport. Physical therapy in sport, 32(1), 1-6.

[11] Dias, T. S., Novotná, K., Oliveira, H. Z., Azevedo, C., Corte-Real, N., Slepička, P., \& Fonseca, A. M. (2018). Why talented athletes drop out from sport? The Portuguese and Czech case. Education+ Training, 60(5), 473-489.

[12] Santos, F. D. S. F. D., Camiré, M., \& Campos, P. H. D. F. (2018). Youth sport coaches' role in facilitating positive youth development in Portuguese field hockey. International Journal of Sport and Exercise Psychology, 16(3), 221-234.

[13] https://ficci.in/spdocument/23041/IISM\%20FICCI\%20Report\%20Final.pdf. 
[14] Chu, T. L., \& Zhang, T. (2019). The roles of coaches, peers, and parents in athletes' basic psychological needs: A mixed-studies review. International Journal of Sports Science \& Coaching, 14(4), 569-588.

[15] Turner, M. J., \& Davis, H. S. (2019). Exploring the effects of rational emotive behavior therapy on the irrational beliefs and self-determined motivation of triathletes. Journal of Applied Sport Psychology, 31(3), 253-272.

[16] Ajaero, C. K., Odimegwu, C. O., Chisumpa, V., \& Obisie-Nmehielle, N. (2017). The influence of internal migration on mental health status in South Africa. International Journal of Mental Health Promotion, 19(4), 189-201.

[17] Martin, N. J. (2020). Fostering Motivation: Understanding the Role Coaches Play in Youth Sport. Strategies, 33(1), 20-27.

[18] O’Neil, L., \& Hodge, K. (2020). Commitment in sport: The role of coaching style and autonomous versus controlled motivation. Journal of Applied Sport Psychology, 32(6), 607-617.

[19] Bolter, N. D., \& Kipp, L. E. (2018). Sportspersonship coaching behaviours, relatedness need satisfaction, and early adolescent athletes' prosocial and antisocial behavior. International Journal of Sport and Exercise Psychology, 16(1), 20-35.

[20] Lefebvre, J. S., Turnnidge, J., \& Côté, J. (2021). A systematic observation of coach leadership behaviors in youth sport. Journal of Applied Sport Psychology, 33(3), 377-386.

[21] Marholz, P. O., Gómez-López, M., Martín, I., Garrido, R. E. R., Garcia-Mas, A., \& Chirosa, L. J. (2016). Role Played by the Coach in the Adolescent Players Commitment. Studia Psychologica, 58(3), 184-198.

[22] Santos, F., Corte-Real, N., Regueiras, L., Strachan, L., Dias, C., \& Fonseca, A. (2017). Portuguese football coaches' role in facilitating positive development within high performance contexts: Is positive development relevant?. International Sport Coaching Journal, 4(2), 147-161.

[23] Dawson, A., Dioth, T., \& Gastin, P. B. (2016). Career facilitators and obstacles of Australian football development coaches. International journal of Sports Science \& Coaching, 11(2), 255269.

[24] Bean, C., \& Forneris, T. (2017). Is life skill development a by-product of sport participation? Perceptions of youth sport coaches. Journal of Applied Sport Psychology, 29(2), 234-250.

[25] Keatlholetswe, L., \& Malete, L. (2019). Coaching efficacy, player perceptions of coaches' leadership styles, and team performance in premier league soccer. Research quarterly for exercise and sport, 90(1), 71-79.

[26] Stoszkowski, J., \& Collins, D. (2016). Sources, topics and use of knowledge by coaches. Journal of sports sciences, 34(9), 794-802.

[27] Harter, S. (1978). Effectance motivation reconsidered. Toward a developmental model. Human development, 21(1), 34-64.

[28] Maslow, A. (1970). Motivation and Personality. 2nd. (ed.) Harper and Row. New York.

[29] Ribeiro, J., Silva, P., Duarte, R., Davids, K., \& Garganta, J. (2017). Team sports performance analysed through the lens of social network theory: implications for research and practice. Sports medicine, 47(9), 1689-1696.

[30] Coccia, M. (2019). Theories of self-determination. Global Encyclopedia of Public Administration, Public Policy, and Governance, Springer International Publishing AG, part of Springer Nature, 91-96. ISBN: 978-3-319-31816-5.

[31] Feltz, L, D., (1998). Self'-Confidence and Sports Performance. Exercise and Sport Science Reviews, 16, 423-457.

[32] Revelle, W., \& Michaels, E. J. (1976). The theory of achievement motivation revisited: The implications of inertial tendencies. Psychological Review, 8(5), 344-401. 
[33] Lonsdale, C., Hodge, K., \& Rose, E. (2009). Athlete burnout in elite sport: A self-determination perspective. Journal of sports sciences, 27(8), 785-795.

[34] Rogaleva, L., Kim, A., \& Khon, N. (2018, December). Motivation of Athletes in Athletics at the Different Stages of the Sports Career. In 1 st International Conference on Contemporary Education and Economic Development (CEED 2018) (pp. 26-30). Atlantis Press.

[35] Chang, W. H., Chang, J. H., \& Chen, L. H. (2018). Mindfulness enhances change in athletes' wellbeing: the mediating role of basic psychological needs fulfillment. Mindfulness, 9(3), 815-823.

[36] Kim, K. W. (2016). Career Decision-Making Self-Efficacy and Career Exploration Behavior by Sports Career of Student Boxers. The Official Journal of the Korean Academy of Kinesiology, 18(3), 35-42.

[37] Kendellen, K., \& Camiré, M. (2019). Applying in life the skills learned in sport: A grounded theory. Psychology of Sport and Exercise, 40(1), 23-32.

$* * * * * * * *$ 